\title{
THERMOSYPHON METHOD FOR COOLING THE ROTOR BLADES OF HIGH-TEMPERATURE STEAM TURBINES
}

\author{
Alexander R. Bogomolov ${ }^{1,}$, Elena Yu. Temnikova ${ }^{2}$ \\ ${ }^{1}$ Kutateladze Institute of Thermophysics SB RAS, Novosibirsk 630090, Russia \\ ${ }^{2}$ Institute of Power Engineering, Kuzbass State Technical University named after T.F. Gorbachev, Kemerovo, \\ 650000, Russia
}

\begin{abstract}
The design scheme of closed two-phase thermosyphon were suggested that can provide standard thermal operation of blades of high-temperature steam turbine. The method for thermosyphon calculation is developed. The example of thermal calculation was implemented, it showed that to cool the steam turbine blades at their heating by hightemperature steam, the heat can be removed in the rear part of the blades by air with the temperature of about $440^{\circ} \mathrm{C}$.
\end{abstract}

\section{Introduction}

To produce electrical power at thermal power stations, the steam turbines with operating temperatures of up to $600^{\circ} \mathrm{C}$ and gas turbines with operation temperatures of up to $1500^{\circ} \mathrm{C}$ are used mainly. The prototypes of high-temperature steam turbines with the working steam temperature of $800-900^{\circ} \mathrm{C}$ appeared not long ago [1-2]. They have the outlooks to increase this temperatures up to $1500-1700^{\circ} \mathrm{C}$ because the efficiency of electricity production depends primarily on temperature and pressure of the working medium in front of the turbounit.

With an increase in the working medium temperature, there can be overheating, altering the structure and properties of the blade metal, which, in turn, may be a source of accidental injury during the operation [3]. Therefore, a significant attention was paid to the process of cooling the gas turbine flow parts [4-6]. The classification of systems and methods for cooling the gas turbine units, including internal, external air and liquid cooling is most fully represented in [6]. The most promising methods of cooling include internal liquid evaporative cooling in the hollow blades by a secondary refrigerant: a two-phase thermosyphon of the closed circuit. The closed two-phase thermosyphons are the devices that can provide standard thermal operation of turbine blades without any additional costs for the work of blowers and without a noticeable reduction in the temperature of operating vapors (gases) in the turbine circuit by blowing air, which cools the blade [6] using a part of the internal volume of blades as a thermosyphon.

If the turbine rotor rotates with a high speed, accordingly the refrigerant (working medium within thermosyphon), which is in the liquid state, moves against the end part of the blade by the centrifugal forces. After supplying high-temperature steam into the turbine, the blades are heated. Heat from a

\section{${ }^{a}$ Corresponding author: teu.pmahp@mail.kuzstu.ru}


high-temperature steam is supplied to the refrigerant, and it (the refrigerant) is turned into vapor, which moves towards the cooling surface in the rear part under the effect of the pressure drop between the zones of evaporation and condensation. In the rear part of the refrigerant vapor is condensed through heat removal, for instance, by air or another coolant flowing in the disk or rotor parts of the turbine. The resulting condensate flows into the end part of the blade by the effect of centrifugal forces.

The study is aimed at the development of the method for calculating a two-phase thermosyphon as a tool for cooling the blades of the high-temperature steam turbine.

\section{Physical model}

The calculation scheme of the closed two-phase thermosyphon is shown in Fig. 1. We assume that heat supply and removal are performed from the ends of the thermosyphon, i.e., there is no heat transfer from the lateral side. The inner closed volume of thermosyphon is cylindrical, its height is $50 \mathrm{~mm}$, diameter is $25 \mathrm{~mm}$, and wall thickness is $5 \mathrm{~mm}$; the blade is made of nickel with $\lambda=72 \mathrm{~W} /(\mathrm{m} \cdot \mathrm{K})$; high-temperature steam enters the turbine with the temperature of $1000^{\circ} \mathrm{C}$; inside the thermosyphone, there is the refrigerant: liquid sodium boils and condenses at the same temperature of $t_{s}=t_{l}=800{ }^{\circ} \mathrm{C}$ [7]; heat from the thermosyphon is removed by air; temperature difference between steam and vapor-liquid sodium is $t_{s t}-t_{s}=200^{\circ} \mathrm{C}$. The heat flux taken from high-temperature steam is spent for the phase transitions of liquid sodium, and finally, it is given to the cooling air. As a result, it is necessary to determine the temperature of the cooling air.

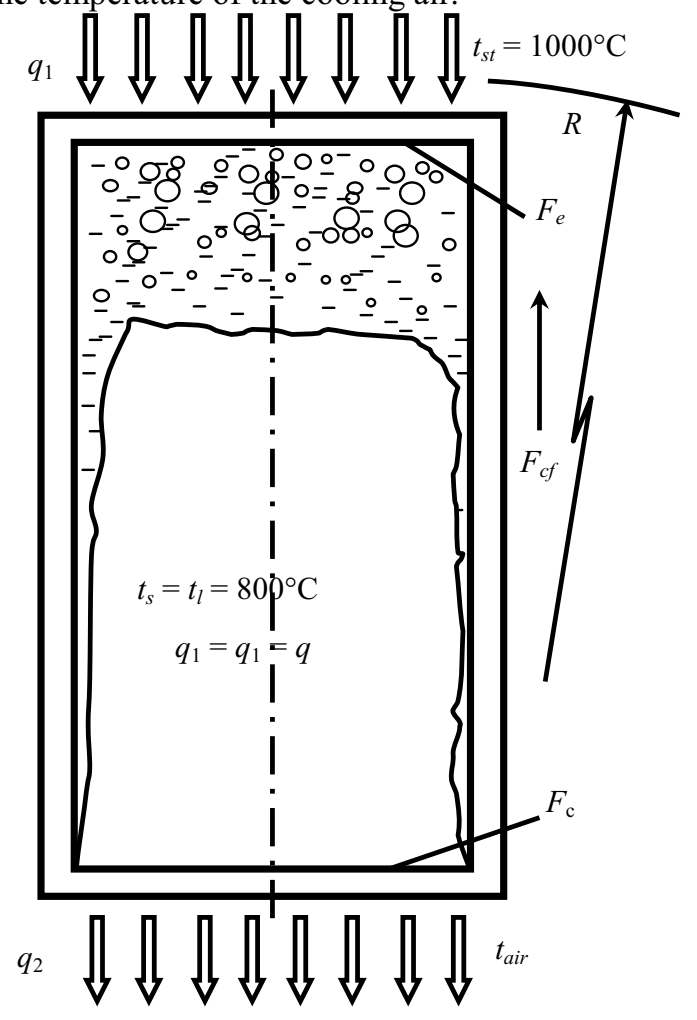

Figure 1. Calculation scheme of thermosiphon. 


\section{Solution and results}

We calculate the coefficient of heat transfer from high-temperature steam to the blade via convection for streamlining a flat surface by [8] $\alpha_{s t}=164.6 \mathrm{~W} /\left(\mathrm{m}^{2} \cdot \mathrm{K}\right)$; where the tangential velocity of steam is $\omega=n R=25 \mathrm{~m} / \mathrm{s}, n=3000 \mathrm{rot} / \mathrm{min}$ is frequency of turbine rotation; $R=0.5 \mathrm{~m}$ is the radius of disc with fixed blades; characteristic linear size is thermosyphon diameter $l=25 \cdot 10^{-3} \mathrm{~m}$; steam properties are assumed for the temperature of $1000^{\circ} \mathrm{C}$.

The density of heat flux transferred from high-temperature steam to the blade surface via convection is $q=32928 \mathrm{~W} / \mathrm{m}^{2}$, and total amount of heat is $Q=16.1 \mathrm{~W}$.

Let us calculate the heat transfer coefficient for boiling sodium at the temperature of $800{ }^{\circ} \mathrm{C}$ by two ways, according to the methods of S.S. Kutateladze [8] and V.I. Subbotin [9].

1) According to S.S. Kutateladze [8], the heat transfer coefficient is $\alpha_{e}=7 \cdot 10^{3} \mathrm{~kW} /\left(\mathrm{m}^{2} \cdot \mathrm{K}\right)$, where Nusselt criterion at evaporation in a volume [8] is $\mathrm{Nu}_{e}=7 \cdot 10^{-4}\left(\operatorname{Re}_{e}^{*} \mathrm{~K}_{p}\right)^{0.7} \operatorname{Pr}_{e}^{0.35}=495$; Reynolds criterion is $\operatorname{Re}_{e}^{*}=q l^{*} \rho_{l} /\left(r \rho_{\text {vap }} v_{l}\right)=8 \cdot 10^{5}$; determining linear size is $l^{*}=\sqrt{\sigma /\left[g\left(\rho_{l}-\rho_{\text {vap }}\right)\right]}=4.1 \cdot 10^{-3}$ $\mathrm{m}$; Kutateladze criterion is $\mathrm{K}_{p}=p l^{*} / \sigma==1700$; at that, pressure is $p=p_{\text {vap }}+m_{l} n^{2} R / F_{e}=51 \cdot 10^{3} \mathrm{~Pa}$; mass of liquid sodium in thermosyphon is $m_{l}=0.3 V \rho_{l}=5.6 \cdot 10^{-3} \mathrm{~kg}$; and volume of thermosyphon is $V=F_{e} \cdot h=2.45 \cdot 10^{-5} \mathrm{~m}^{3}$, where $F_{e}=F_{c}=\pi d^{2} / 4 ; m_{l} n^{2} R=F_{c f}$

2) According V.I. Subbotin, heat transfer coefficient is $\alpha_{e}=2.65 \cdot 10^{3} \mathrm{~kW} / \mathrm{m}^{2} \cdot \mathrm{K}$ ), where $\mathrm{Nu}_{e}=0.38\left(\mathrm{Gr}_{e} \operatorname{Pr}_{e}^{2}\right)^{1 / 3}=1.15 \cdot 10^{3}$, and instead of acceleration of gravity we took acceleration $a=\omega n=n^{2} R$.

As it can be seen, the order of $\alpha_{e}$ obtained by two methods differs almost twice, but this difference hardly affects the heat transfer coefficient.

The coefficient of heat transfer from steam to boiling sodium through the separating wall is $k_{1}=156.6 \mathrm{~W} /\left(\mathrm{m}^{2} \cdot \mathrm{K}\right)$. Then, the amount of heat transferred through the end surface of thermosyphon from steam to boiling sodium is $Q=15.35 \mathrm{~W}$, and the difference between this value and heat transferred from high-temperature steam to the turbine blade via convection is less than $5 \%$.

The heat transfer coefficient at film condensation of sodium on the lower cooled surface $F_{c}$ of a horizontal plate, according to equation

$\frac{\alpha_{c}}{\lambda_{l}}\left[\frac{\sigma}{g\left(\rho_{l}-\rho_{\text {vap }}\right)}\right]^{\frac{1}{2}}=0.15\left[\frac{v_{l}}{a_{l}} \frac{g}{v_{l}^{2}}\left(\frac{\sigma}{g\left(\rho_{l}-\rho_{\text {vap }}\right)}\right)^{\frac{3}{2}}(1-\tilde{\rho}) \frac{r}{c \Delta T}\right]^{1 / 4}$, with assumed $\Delta T=5 \quad \mathrm{~K}, \quad$ is $\alpha_{c}=1.55 \cdot 10^{5} \mathrm{~W} /\left(\mathrm{m}^{2} \cdot \mathrm{K}\right)$.

Then, the coefficient of heat transfer from the blade to air via convection at streamlining the flat surface $\left(F_{c}\right)$ is $\alpha_{\text {air }}=92 \mathrm{~W} /\left(\mathrm{m}^{2} \cdot \mathrm{K}\right)$, the properties of air are assumed for the temperature of $500^{\circ} \mathrm{C}$.

The coefficient of heat transfer from condensing sodium vapor to cooling air through the wall is $k_{2}=91.4 \mathrm{~W} /\left(\mathrm{m}^{2} \cdot \mathrm{K}\right)$.

The middle temperature of air supplied to the volumes of the disc or rotor parts for heat removal will be $t_{\text {air }}=t_{s}-q / k_{2}=440^{\circ} \mathrm{C}$.

\section{Conclusion}

The design scheme of closed two-phase thermosyphon and the method for thermosyphon calculation were suggested; the example of thermal calculation was implemented, it showed that to cool the steam turbine blades at their heating by high-temperature steam, the heat can be removed in the rear part of 
the blades by air with the temperature of about $440^{\circ} \mathrm{C}$. The method for cooling the turbine blades using the two-phase closed thermosyphons should be implemented at the stage of manufacturing the blade sets after thorough experimental studies

\section{References}

1. B.A. Shifrin, Proc. of Russian National Conference on Heat Transfer-4, 1, 266 (2014)

2. B.A. Shifrin, O.O. Milman, V.A. Fedorov, R.A. Tokar, High-temeparture steam turbine (RF patent 2311540, No. 2006102804/06)

3. D.A. Kazanskii, A.M. Klypina, L.D. Chistyakova, Thermal Engineering, 6, 519 (2011)

4. S.V. Tsanev, Gas-Turbine and Vapor-Gas Installations of Thermal Power Plants (Tutorial for High Schools, Moscow: MEI, 2009)

5. A.I. Leontiev, Heat Transfer Apparatuses and Cooling Systems for Gas-Turbine and Combined Installartions (Tutorial for High Schools, Moscow: MSTU, 2004)

6. Al-Ani Maaz Abdulwahed Zib, The features of hydrodynamics and heat and mass transfer in thermosyphons for application in thermal-power equipment (Theses for defending dissertation of the candidate of technical sciences. Tomsk, 2011)

7. P.D. Dan, Heat Pipes (Moscow: Energiya, 1979)

8. S.S. Kutateladze, Fundamentals of Heat Transfer (Academic Press, New York, 1963)

9. V.I. Subbotin, Heat Transfer in Metal Boiling by Natural Convection (Moscow: Nauka, 1969) 